\title{
Research on Interdisciplinary Expression Forms Derived from Animation
}

\author{
Dandan Luo ${ }^{1}$, Min Huang ${ }^{1, *}$ \\ 1. South China Normal University, Guangzhou,510631, China
}

\begin{abstract}
Animation art is displayed in front of people in the form of images, and people have long been accustomed to attribute it to image art similar to movies. In a narrow sense, the expression form of animation is really single. If we look at generalized animation from the original intention of animation, animation has a broader development space, and there are more derivative possibilities of interdisciplinary combination. Nowadays, it is a pluralistic society, and the freedom, openness and integration of disciplines has become a trend. Starting from summarizing the three commonalities (story, role and performance) derived from the interdisciplinary animation, this paper discusses various possibilities of the interdisciplinary expression forms derived from animation through practical cases.
\end{abstract}

\section{Introduction}

Animation art is displayed in front of people in the form of images, and people have long been accustomed to attribute it to image art similar to movies. Whether it is classified two-dimensional animation, three-dimensional animation or freeze-frame animation, its final display form is video in traditional understanding, and it is carried by television, cinema and network. In a narrow sense, the expression form of animation is really single. If we go back to the early days of animation, in 1893, French artist Emile Renault played "Pauvre Pierrot" in Musee Grevin, Paris, using the self-made broadcasting equipment "Pantomimes Lumineuses" [1], marking the birth of this fantasy art. The predecessor of "Pantomimes Lumineuses" is the "magic slide" which prevailed in Europe from 17th to 19th century. At that time, street drama performers used it to perform in urban roadways, making projection images combined with human body performances, rendering atmosphere and telling stories with smoke candlelight. Animation and drama may have been inextricably linked, and the birth of animation has interdisciplinary meaning. "English Animation of animation originates from the Latin radical anima, which means soul, and the verb animare is to give life" [2] We can see that the original intention of animation is to create life, give kinetic energy to inanimate things and tell stories. If we look at generalized animation from the original intention of animation, animation has a broader development space, and there are more derivative possibilities of interdisciplinary combination. Nowadays, it is a pluralistic society, and the freedom, openness and integration of disciplines has become a trend. For example, in recent years, the Ministry of Education has attributed animation, which was originally a design subject, to a sub-discipline under drama and film and television. This fantastic art has opened up the dream-making mechanism of human beings and realized various dreams in ever-changing forms. This paper discusses the new manifestation of this ancient art by summarizing the common characteristics of the interdisciplinary derivative possibilities of animation and doing practical research.

\section{Attitude towards animation}

The audience has strong initiative in choosing animation works and obvious differentiation of personality, and each type of animation works has different audience groups. There are many factors that influence this choice. Through the statistics of 415 samples, the author found that the majority of people like Japanese animation. Among all the respondents, 140 people choose "very like", 126 people choose "like", and 101 days choose "like", and the three options together account for $88.6 \%$.

This result is consistent with the data and research background collected by the author in the early stage. It can be seen that Japanese animation is not only popular in Beijing, Shanghai, Guangdong and other places. Further analysis of the correlation between gender, age and attitude shows that gender and grade have little influence on attitude. 
Table 1. Correlation analysis between gender and preference level

\begin{tabular}{llll}
\hline \multirow{3}{*}{ Gender } & & Gender & Favorite layering \\
\cline { 2 - 4 } & Pearson Correlation & 1 & -.0214 \\
\cline { 2 - 4 } & Sig. (2-tailed) & .001 & .556 \\
\cline { 2 - 4 } Favorite layering & $\mathrm{N}$ & 415 & 415 \\
\cline { 2 - 4 } & Pearson Correlation & -.020 & .001 \\
\cline { 2 - 4 } & Sig. (2-tailed) & .438 & 415 \\
\cline { 2 - 4 } & $\mathrm{N}$ & 415 & .00 \\
\hline
\end{tabular}

Table 2. Correlation analysis between age and preference level

\begin{tabular}{llll}
\hline & & Grade & Favorite layering \\
\hline \multirow{3}{*}{ Grade } & Pearson Correlation & 1 & -.018 \\
\cline { 2 - 4 } & Sig. (2-tailed) & .001 & .814 \\
\cline { 2 - 4 } & $\mathrm{N}$ & 415 & 415 \\
\hline \multirow{3}{*}{ Favorite layering } & Pearson Correlation & -.017 & .001 \\
\cline { 2 - 4 } & Sig. (2-tailed) & .771 & 415 \\
\cline { 2 - 4 } & $\mathrm{N}$ & 415 & \\
\hline
\end{tabular}

The above results show that Japanese animation is widely loved by different age groups and different genders, and most people's cognition of animation stays in this type of animation. Breaking the barriers of singularity, enriching the connotation of animation, and exploring the possibility of derivative methods of animation from multiple angles are the main thrust of this article.

\section{Common characteristics derived from interdisciplinary animation}

\subsection{Story and theme}

A story is the soul of an animation. A good animation pays more attention to its content rather than the simple picture effect. Picture style, narrative technique, and lens application all serve only one purpose: story expression. It can be seen that story is the most important element in animation composition. Of course, there is another kind of animation, such as abstract animation and artistic animation, whose focus is replaced by theme, but no matter what kind of animation, story and theme are necessary components. Looking at all kinds of art disciplines, we will find that the works are story-telling and themeoriented, which is not unique to animation. The art of picture books and illustrations in graphic design disciplines is most easily associated, which emphasizes narrative expression through a series of images. Many excellent picture book authors are also animation artists. For example, Chen Zhiyong, an Australian Chinese picture book writer, whose masterpiece "The Lost Thing" has a picture book and an animated version. Another example is puppet play in drama, also commonly known as puppet play, which originated from the 5th century BC. This kind of play, which has existed for a long time in both Chinese and Western drama circles, has essential commonness with animation, namely "story" and "expression". It can be seen that there are similarities in narrative themes between animation and many art disciplines.

\subsection{Role plastic arts}

Creating characters is the second indispensable element in animation art. Returning to the original intention of animation mentioned above, it is people's good wishes for animation to create things that do not exist and give them the attributes of characters. However, this feature is not unique to animation. Before the birth of animation, human beings made various similar attempts. Automata[3] (figure 1) is an example. This kind of mechanical device, which prevailed in European aristocratic families in the 18th and 19th centuries, was driven by clockworklike clockwork, and designed various interesting characters or animal characters in extremely exquisite scenes to perform with preset actions. Before the animation was born, it and puppet show satisfied the desire of human beings to create role performances. Up to now, creating characters is not unique to animation, but exists in various art disciplines, such as the "Doll" (Figure 2) series of female doll characters with ball joints created by German sculpture and installation artist Hans Bellmer in 1934, which pioneered the creation of attractive figures. By manipulating these mutilated human limbs, he made various movements to shoot, giving them life representation images. 


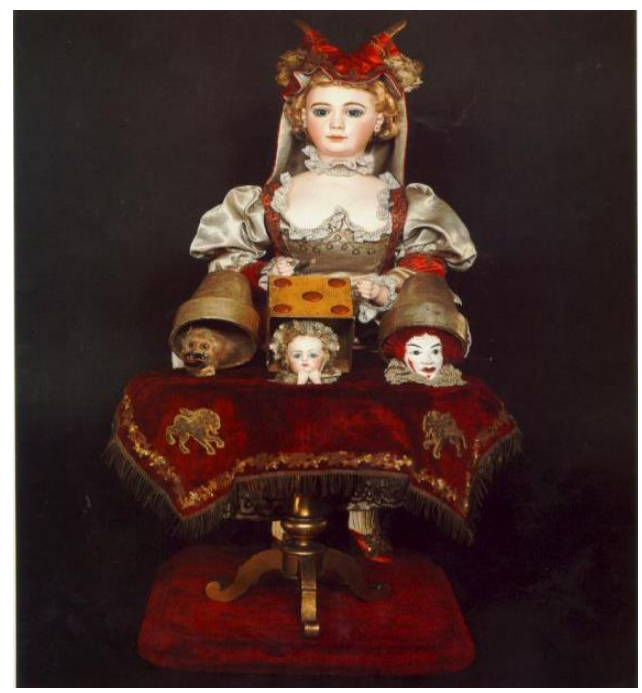

Figure. 1. Automata details

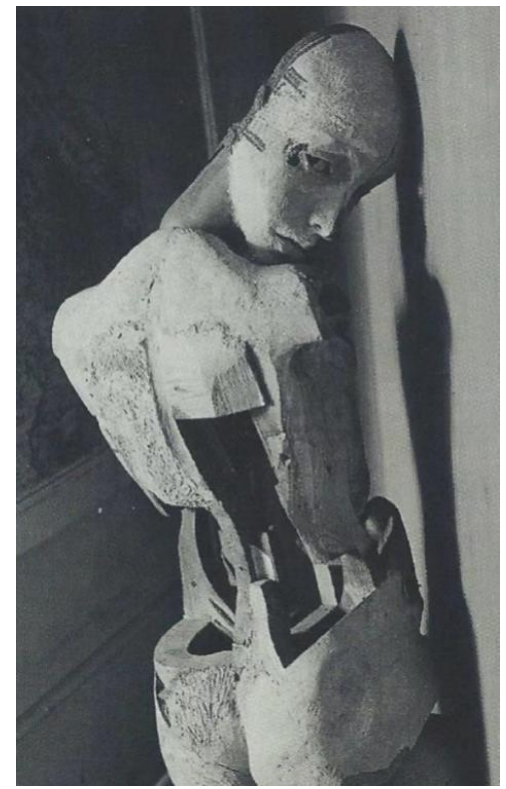

Figure. 2. Picture of "Doll"

\subsection{Performance and display}

Character performance and story display in animation are important elements that distinguish animation from real images, and are the third important feature of animation. In performance and exhibition, the common factors between animation and disciplines are easier to discover. Nowadays, animation shows can be seen everywhere, such as cinemas and film festivals, but there are also various small occasions, such as the screens of shopping malls, public leisure spaces, public facilities aisles and so on. Similar to it, such as drama, as mentioned in "Understanding Drama", the performance of today's drama "can be a modern theater, or a temporary theater converted from attic, fire station, church or warehouse. Sometimes plays are performed indoors and sometimes outdoors; Some plays and musicals have exquisite scenery, while others have only a simple stage. " [4] On the performance, such as the street performance of Little Theatre of
Doll, a puppet troupe composed of British visual artists Raisa Veikkola and Frida Alvinzi (Figure 3). What his works show us is based on the traditional marionette, combined with real-life performances, pulp, paper art, clay, cloth art, and the reorganization and utilization of ready-made items, which is very similar to the way of freeze-frame animation in animation. A similar and more extreme example is the Royal de Luxe (French Royal Luxury Giant Puppet Troupe) (Figure 4). Every time a giant puppet with a height of several meters is manipulated, it performs according to the story in the city, and the form is extremely free. In addition to drama, there are a variety of disciplines and animations showing performance attributes. For example, Roger Ballen's photographic work "Roger the Rat" (Figure 5), the author created the role of mouse man with independently created mouse headgear and various props, discussed the theme of human social pressure, and designed a series of performance picture plots. 


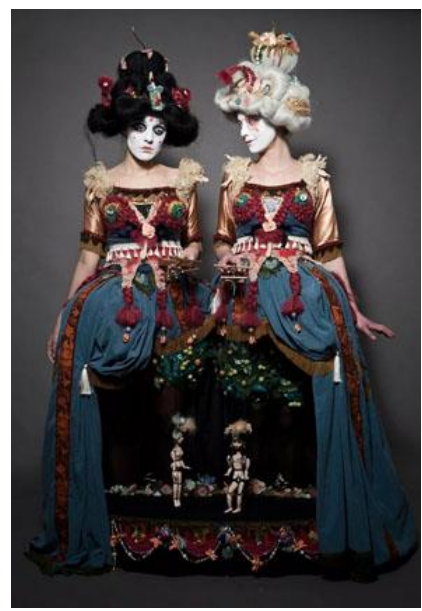

Figure. 3. A puppet troupe composed of British visual artists Raisa Veikkola and Frida Alvinzi

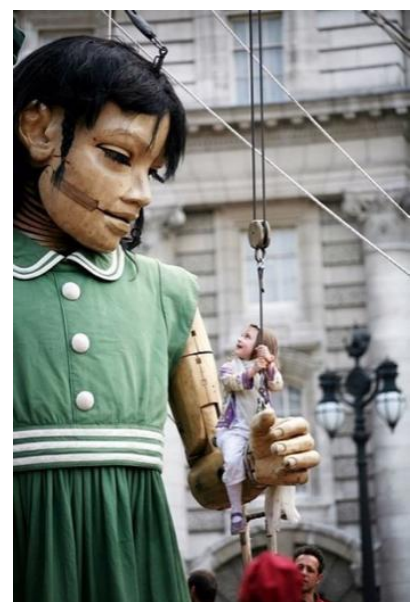

Figure. 4. The Royal de Luxe (French Royal Luxury Giant Puppet Troupe)

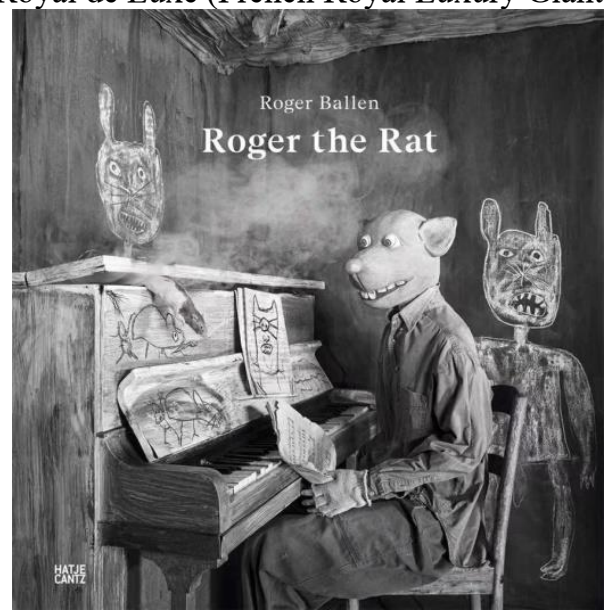

Figure. 5. "Roger the Rat"

4. Practice of interdisciplinary performance research derived from animation

According to the above summary of the commonness between animation and multi-disciplines, I explore the possibility of animation derivation. Through the following two practical experiments, the interdisciplinary performance derived from animation is further studied.

\subsection{The combination of animation and dramatic art}

Drama and animation have some common characteristics in story, role and performance. In order to study the interdisciplinary derivative expression form of animation, I took the opportunity of participating in Wuzhen Drama Festival in 2018 to organize a practical experiment for students of Grade 16 animation in Digital Media Art Department of South China Normal University. According to their homework of animation script creation, the 
students selected the story "The Little Monster in the Cracks in the Wall". The synopsis of the story is that a child gradually loses the ability to imagine the stains in the cracks in the wall when he grows up, implying that he is mature but loses his innocence. This story has a lot of imagination in modeling elements, which can give full play to the advantages of animation majors in character modeling design. Considering that drama needs more exaggerated performance and conflict, this performance is set as a giant puppet controlled by real people, and the script is adapted. Three clever protagonists, Bobo Taotao and Weird Wall Cracks, were designed: the little beauty who loves beauty, the fat man who is greedy, and the leader of Candy Town, Mr. Sugg Switt. In the form of street performance, it is assumed to exist in a wall crack world called "Candy Town", which is suitable for the performance venue in Wuzhen Lane. As a derivative expression of the combination of animation and drama, I emphasize the fantasy of the story, enrich the complexity of character modeling, and make diversity of materials and means, so as to distinguish it from ordinary drama performances. The comprehensive material means of freeze-frame animation is used to make the face and limbs of the doll. The waste newspaper and latex are mixed and pasted (Figure 6), and the control mechanism is set. The interdisciplinary cooperation with the teachers and students of the clothing department enabled us to finish the doll production in more than one month. However, the biggest difficulty of animation-derived drama expression lies in the stiff and boring limbs of live-action performances. The students of animation department have no basis for live-action performances and need professional drama performance guidance. The joining of drama students has solved the difficult problems. Through performing together with drama students, animation students have a better understanding of the true meaning of performance, which is beneficial to future animation creation.

This is a bold attempt. Through this experiment, I can prove the feasibility of combining animation with drama art, and based on commonality, give new ideas and ideas to drama according to the characteristics of animation, and get interesting and diversified animation derivative forms.

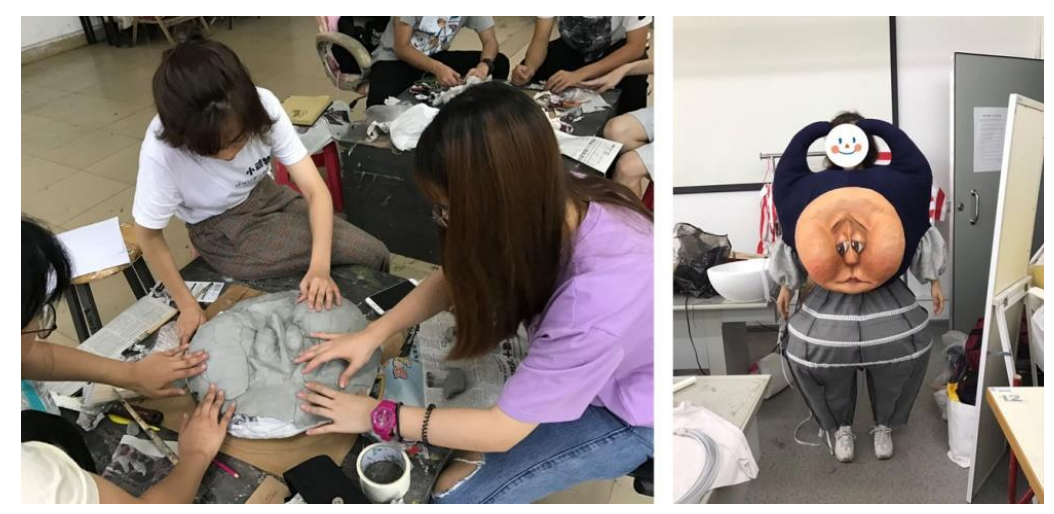

Figure. 6. The mixed and pasted newspapers

\subsection{Combination of animation and installation art}

The story theme and role creativity of animation have been analyzed, which is not unique to animation. Installation sculpture and animation art have common characteristics in this respect. In 2020, I took the opportunity of organizing the exhibition of the collection achievements of 19th-grade students in the Department of Digital Media Art of South China Normal University to study the interdisciplinary derivative performance of animation in this respect. For the purpose of training students' role modeling ability, we chose the ceramic workshop in Jingdezhen, Jiangxi Province to study. After returning, a large number of creative ceramic works need to be displayed. I think that ceramic modeling itself has the artistic characteristics of installation with material implication, and it is possible to set up themes and large-scale installations matched with them to enrich the display effect as another interdisciplinary derivative performance experiment of animation. Starting from the thinking of animation, it is necessary to set a theme or think of a story first. The firing characteristics of ceramics need the experience of fire. "Bathing fire" has become the basis of our theme, which can be related to each other and implies the changes of students' mood. Starting from the theme, combined with the installation exhibition needs to have a guide route, the overall layout of the exhibition hall of the Academy of Fine Arts is divided into five areas, the materials are searched from the photos during the journey, and the story-telling pictures are excavated for each area. Finally, the giant installations in the three areas were established, and a tour route with both ornamental and interesting stories was designed. From the small kiln to the big chimney, and then through the giant cave, the viewer experienced a journey of ceramic firing. This overall design with strong story is different from the traditional installation art, and it is a unique performance derived from animation. The addition of conceptual and moral features of installation art enriches the modeling. For example, the big chimney itself is no longer the restoration of reality. This inspiration comes from the factory chimney site in Taoxichuan Creative Park, Jingdezhen. It only takes its large shape, weakens the details, and adds three large faces with vacant eyes and ears to place ceramic exhibits, implying three important openings in the sensory world. Finally, the props of large-scale devices adopt the low-cost and easy-to-realize methods: build the skeleton with iron wire, shape the newspaper group, seal the net outside, paste paper pulp, and polish it with pro- 
pylene and toner. (Figure 7) This method is also based on the creation technique of even-body characters in stopmotion animation, which is a derivative attempt of animation technique applied to large-scale devices. Through the joint efforts of teachers and students, many largescale installation sculptures up to two meters have been realized (Figure 8), and the exhibition has also received favorable response, which reflects the success of this interdisciplinary derivative experiment of animation and installation art.

Through this experiment, I can confirm the feasibility of the combination of animation and installation art, which is similar to the combination of drama, based on commonality, and reflects the unique characteristics of animation derivative performance and the integration of traditional installation art.
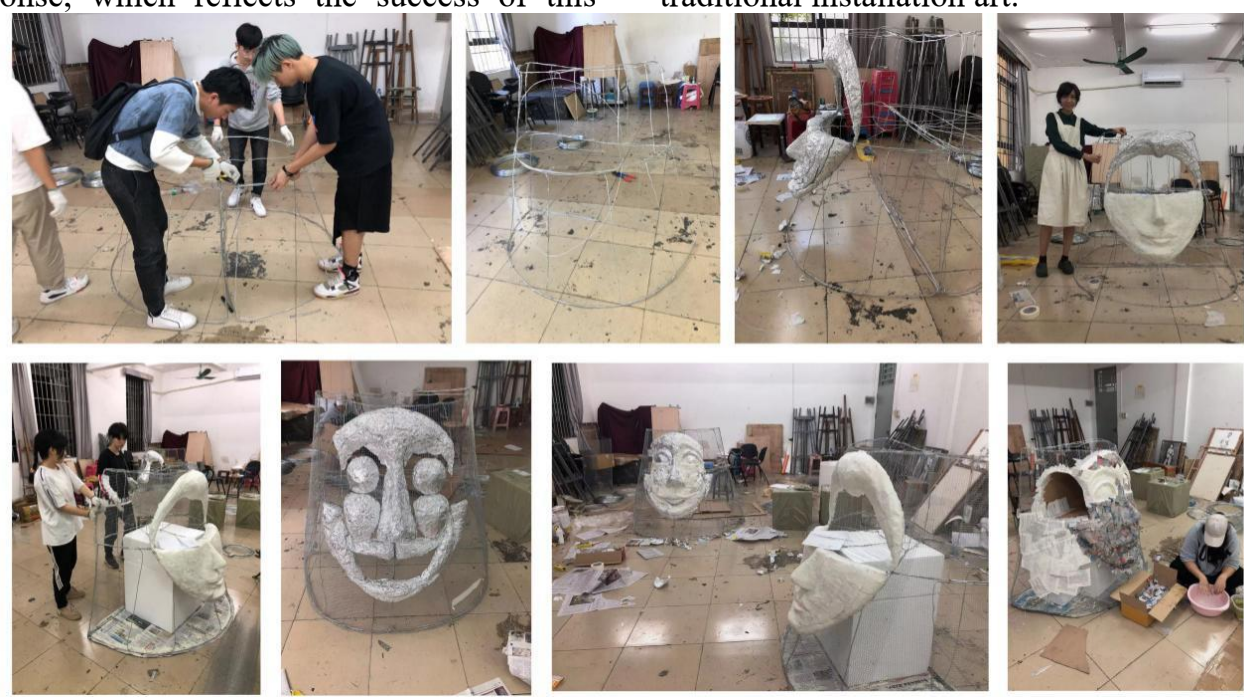

Figure. 7. The process of building
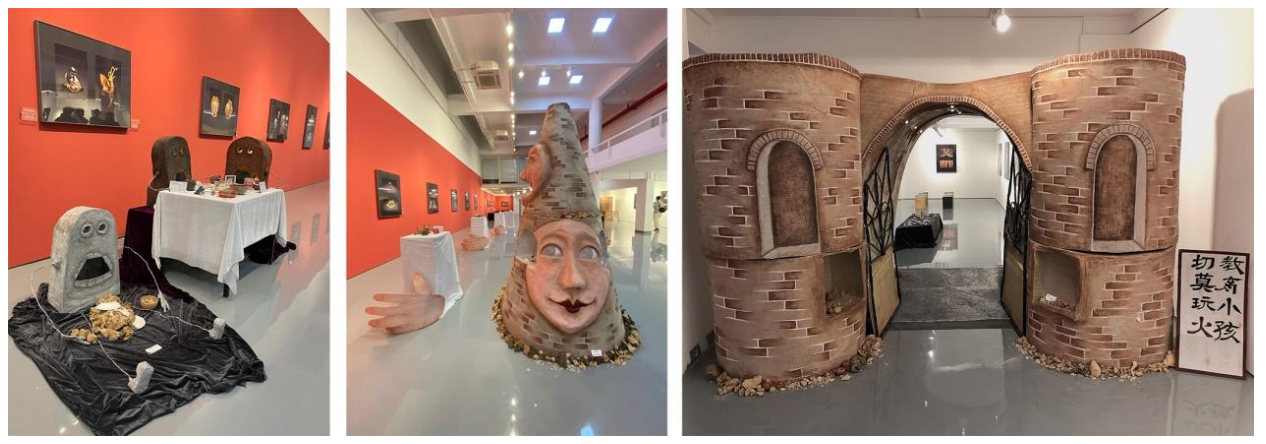

Figure. 8. The exhibition of final product

Guangdong Provincial Department of Education" (project

\section{Conclusion}

With the development trend of diversified and open society, there are more cross-border cooperation needs among disciplines, and the boundaries between disciplines are becoming increasingly blurred. As an ancient art with a history of 100 years, animation may need new blood to explore more possibilities. Starting from animation in a broad sense, this paper intends to discuss the common characteristics between animation and multidisciplines, and a variety of potential development cooperation possibilities, and proves its feasibility with practical examples. Animation is no longer a simple image art, it can have more diversified derivative expressions.

\section{Acknowledgements}

This article is the research result of "2018 Youth Innovative Talents Project (Humanities and Social Sciences) of number: 2018WQNCX016)

\section{References}

1. $\mathrm{Yu}$ Weizheng, animation notes [M]. Beijing: Ocean Press, November 2009

2. Wang Xiru, Wang Rui. Experimental animation [M] Chongqing: Southwest Normal University Press, 2015

3. Maureen Furniss, Introduction to Animation [M] Beijing: China Youth Publishing House, 2009

4. Edwin Wilson, Understanding Drama [M] Chengdu: Sichuan People's Publishing House, 11th Edition 